\title{
THE SECRETION OF GASTRIC MUCIN IN MAN. A COMPARATIVE STUDY IN THE NORMAL SUBJECT AND IN THE PATIENT WITH PEPTIC ULCER IN RE- SPONSE TO AN ALCOHOL TEST MEAL
}

\author{
By R. K. ANDERSON AND S. J. FOGELSON \\ (From the Department of Experimental Surgery and Biochemistry, Northwestern University \\ Medical School, Chicago)
}

(Received for publication October 16, 1935)

The protective and lubricative rôle of mucus in the gastro-intestinal tract has been reported and studied by many investigators (Claude Bernard (4), Schiff (18), de Klug (12), Whitlow (19), Elliott (7), Pavlov (16), Berg and Jobling (3), Leriche (14), and Bucher (6)). An absolute or relative deficiency of gastric mucus has been frequently suggested as a possible etiologic factor in gastro-duodenal ulcerative disease (Leriche (14), Bucher (6), and Kaufmann (11)).

More recently Hurst (10) has concluded that 10 per cent of all individuals are predisposed to ulcer because they have hypersthenic stomachs which secrete an excess of highly acid gastric juice low in visible mucus. He may be quoted, "Moreover, owing to the deficient power of secreting mucus which is characteristic of the hypersthenic stomach, the protection against damage afforded by a layer. of mucus in the hyposthenic stomach is absent." These individuals have gastro-duodenal mucosa which can tolerate normal irritation but when faced with " extraordinary or unusual exigencies will as a result of their hypoprotection secondary to mucus deficiency tend to develop ulcer. It has been suggested that this absence of mucus is due to its digestion by gastric juice but mucus differs from other proteins in the extreme slowness with which it undergoes peptic digestion." The resistance of mucus to peptic digestion has been confirmed by one of us (R. K. A.).

The object of this investigation was to determine quantitatively whether the gastric contents of a patient with duodenal ulcer has less mucus after a standard stimulus than is found in the stomach of the average individual.
METHOD

The first prerequisite was an accurate method for the quantitative estimation of relatively small quantities of mucus. According to Levene (15), gastric mucin is composed of a carbohydrate prosthetic group, mucoitin sulfuric acid, in combination with protein. The components of mucoitin sulfuric acid he believes to be two molecules each of glucosamine, glucuronic acid, sulfuric acid and acetic acid. Komarov (13) has recently presented data in support of this composition, and we have obtained some experimental evidence tending to further substantiate it.

Since glucosamine and glucuronic acid are both reducing substances, it is possible to estimate mucin quantitatively by the reduction obtainable after they have been freed from their combination in the mucoitin sulfuric acid by means of acid hydrolysis. For the estimation of this reducing power we have used the Somogyi-ShafferHartmann method (Peters, and Van Slyke (17)). Details of our procedure have been previously published (1). Due probably to the difficulties encountered in purifying gastric mucin, the values for its reducing power (after acid hydrolysis) reported in the literature show considerable variation. In view of this fact, and since we are interested here in comparative values only, we made no attempt to convert reducing values to true mucin values, expressing all our results in terms of milligrams of reducing substance (expressed in terms of glucose) per cubic centimeter of gastric juice. This method has been previously described in detail and has been shown to yield consistently uniform results which renders it valuable for the comparative purposes of our study.

For stimulation of gastric secretion, $240 \mathrm{cc}$. of 
7 per cent alcohol were introduced at about 8 a.m. into the fasting stomachs of the subjects through a Rehfuss tube. Alcohol was used rather than the customary Ewald meal because alcohol interferes in no way with the reduction method. Histamine was eliminated as a gastric stimulant inasmuch as Webster (2) has shown that it promotes the secretion of a gastric juice high in acid and low in mucin, and because it was thought the alcohol might evoke a larger secretion of mucus. After the Rehfuss tube was passed, the patients were taught to expectorate any oral secretions thus avoiding salivary contamination. Whenever possible a resting specimen was ob- adults between 25 and 30 years of age with no gastro-intestinal symptoms or a history of previous gastro-intestinal disturbance. They were apparently in perfect health. Using the technic described the average reducing substance (calculated as glucose) per cubic centimeter of gastric juice averaged between .4 and $.7 \mathrm{mgm}$. (Figure 1). It was interesting to note that most of these normal individuals showed a striking similarity in the content of reducing substance per cubic centimeter of gastric juice on studies done at varied intervals.

The 68 patients with definite roentgenographic findings and classic histories of duodenal ulcer

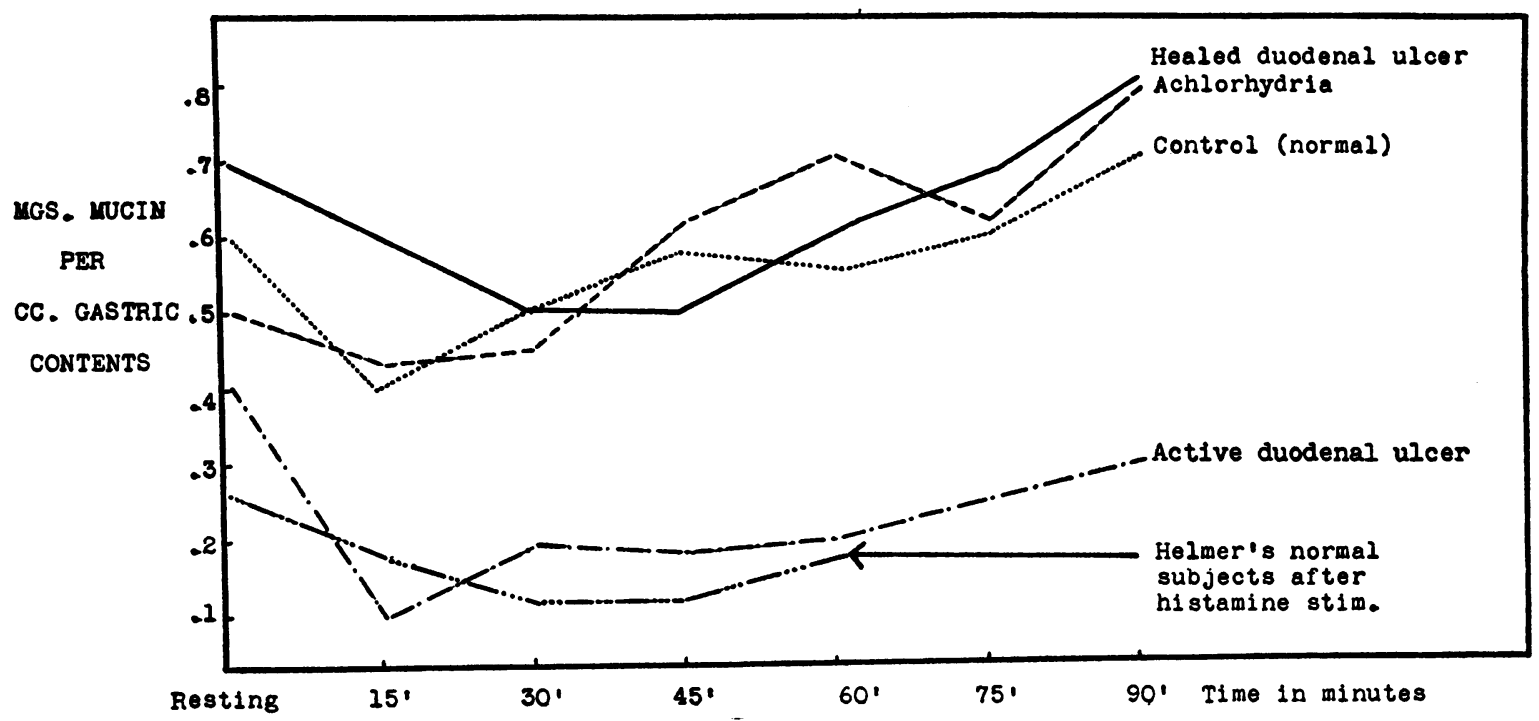

Fig. 1. Determinations of Gastric Mucin after Alcohol Test Meal.

At 15 minute intervals the mucin values per cubic centimeter of gastric contents were determined and charted in terms of milligrams per cubic centimeter of reducingsubstance (calculated as glucose).

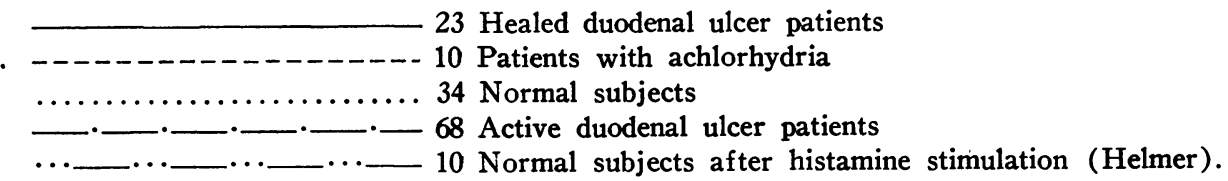

tained, and the stomach emptied. The alcohol was quickly introduced through the Rehfuss tube after which a $10 \mathrm{cc}$. sample was removed. Ten cc. samples were then removed at fifteen minute intervals for at least two hours or until the stomach was empty. The samples were then titrated and assayed for mucin content.

\section{RESULTS}

The normal controls consisted of 33 young showed, prior to institution of gastric mucin therapy, much lower figures, having consistently between .1 and $.3 \mathrm{mgm}$. of reducing substance (calculated as glucose) in each cubic centimeter of gastric juice (Figure 1). It is again noteworthy that repeated determinations in these individuals demonstrated a striking similarity in the reducing substance curve. Twenty-three of the ulcer patients with originally low mucin secretory curves ( .1 to $.3 \mathrm{mgm}$. of reducing substance per 
cubic centimeter of gastric juice), were submitted to reinvestigation after three months of therapy during which period the sole medication used was 50 grams of gastric mucin suspended in milk and cream, divided into 12 doses and taken at hourly intervals throughout the day. Gastric secretion was again stimulated by the $240 \mathrm{cc}$. of 7 per cent alcohol introduced at 8 a.m. into the fasting stomachs of the subjects through a Rehfuss tube. These patients, now symptom-free, showed a curve with from .6 to $.8 \mathrm{mgm}$. of reducing substance (calculated as glucose) per cubic centimeter of gastric juice. The curve now obtained, as can be seen from Figure 1, was very similar to that of the controls.

In addition 10 patients with achlorhydria, 3 of whom were untreated cases of pernicious anemia, showed in response to a similar alcohol test meal a mucin secretory curve simulating that of a normal individual. This is reported in order to contrast these patients with those suffering from duodenal ulceration.

\section{DISCUSSION}

This study shows that in terms of response to the alcohol test meal there is a relative mucin deficiency in the ulcer patient when contrasted with that of the normal subject. When a normal individual is stimulated with histamine the gastric secretory response is high in acid and low in mucin. Using the results published by Helmer. (9), on normal individuals on whom histamine was used, and expressing his mucin values in terms of the same units we used, we found that his normal individuals have a mucin content per cubic centimeter of gastric secretion which closely simulates our figures for the ulcer patient with an active duodenal lesion. It would appear that the stomach of the ulcer patient secretes a gastric juice similar to that secreted by the normal subject following histamine stimulation. When an ulcer patient is symptom-free and apparently healed the hypersecretion of acid fluid is corrected and then the quantity of mucin (measured as glucose) per cubic centimeter of gastric contents approaches normal. Despite the fact that subjects with achlorhydria showed practically a normal mucin secretory curve, they are really hyposecreters of mucus because the diluting acid fluid is absent.
We have attempted to answer the question of whether these mucin deficiencies were relative or absolute by using the technic of Bloomfield and Keefer (5), but to date our results have not justified definite conclusions. This phase of the subject is being further investigated.

\section{CONCLUSIONS}

The quantitative measurements of gastric mucin in ulcer patients with active lesions has shown that there is a relative mucin deficiency per cubic centimeter of gastric contents in response to an alcohol test meal. This is in agreement with the hypothesis of Hurst (10), based on qualitative observations, that there exists in the ulcer patient with an active duodenal lesion a hypo-protection as a result of a relative mucin deficiency. Quantitative evidence is also supplied that such a deficiency of mucin with its attendant hypo-protection may be corrected by feeding these patients gastric mucin and thus establishing a normal relationship between the acid and mucin components of their gastric content.

\section{BIBLIOGRAPHY}

1. Anderson, R. K., Fogelson, S. J., and Farmer, C. J., Gastric mucin secretion in gastro-duodenal ulcerative disease. Proc. Soc. Exper. Biol. and Med., 1934, 31, 520.

2. Webster, D. R., Changes in the composition of the gastric juice under different stimuli. Tr. Roy. Soc. Canada, Sect. V, 1931, 25, 213.

3. Berg, B. N., and Jobling, J. W., Biliary and hepatic factors in peptic ulcers, an experimental study. Arch. Surg., 1930, $20,997$.

4. Bernard, C., Leçons sur la physiologie et la pathologie du système nerveux. Volume II. J. B. Baillière et fils, Paris, 1858.

5. Bloomfield, A. L., and Keefer, C. S., A method for the continuous quantitative estimation of gastric secretion and discharge in man. Arch. Int. Med., 1926, 37, 819.

6. Bucher, R., Das Wesen der Schutzwirkung des Magenschleims. Deutsche Ztschr. f. Chir., 1932, 236, 515.

7. Elliott, E. C., A study of the effect of gastric mucin on peptic digestion. Master's thesis, Northwestern University (Unpublished).

8. Florey, H. W., and Harding, H. E., The functions of Brunner's glands and the pyloric end of the stomach. J. Path. and Bact., 1933, 37, 431.

9. Helmer, O. M., The relation of the secretion of mucus to the acidity of the gastric juice. Am. J. Physiol., 1934, 110, 28. 
10. Hurst, A. F., The unity of gastric disorders. Brit. M. J., 1933, 2, 89.

11. Kaufmann, J., Lack of gastric mucus (amyxorrhoea gastrica) and its relation to hyperacidity and gastric ulcer. Am. J. M. Sc., 1908, 135, 207.

12. Klug, de F., Pourquoi les ferments protéolytiques ne digèrent-ils pas l'estomac et l'intestin sur le vivant? Arch. internat. de physiol., 1907, 5, 297.

13. Komarov, S. A., Isolation of mucoitinsulfuric acid from canine gastric juice. J. Biol. Chem., 1935, 109, 177.

14. Leriche, R., Nécessité d'une étude systematique de la fonction des glandes a mucus du point de vue de la physiologie, de la pathologie et de la thérapeutique. Presse méd., 1932, 40, 650.

15. Levene, P. A., Hexosamines and mucoproteins. Longmans, Green and Co., New York, 1925.

16. Pavlov, I. P., The Work of the Digestive Glands. J. B. Lippincott Co., Philadelphia, 1910.

17. Peters, J. P., and Van Slyke, D. D., Quantitative Clinical Chemistry. Volume II. Methods. Williams and Wilkins Co., Baltimore, 1932.

18. Schiff, J. M., Leçons sur la physiologie de la digestion. Volume II, H. Loescher, Paris, 1867.

19. Whitlow, J. E., The protective action of mucus. Master's thesis, Loyola University (Unpublished). 